\title{
ISLAM SEBAGAI IDEOLOGI ALTERNATIF DI ABAD KEDUA PULUH SATU
}

\author{
Syaikb Musa Abd. Latif al-Shabiby*) \\ Alih bahasa oleh : Mubammadiyab Dja'far*)
}

\section{PENDAHULUAN}

Islam adalah satu-satunya agama sawawi yang diturunkan ke segenap umat manusia, tanpa memandang jenis kebangsaan, warna kulit, bahasa, asal-usul, dan zamannya. Islam adalah risalah yang bermuatan makna misi alamiah. Alamiah adalah suatu kalimat yang mempunyai arti yang dalam, indah, dan agung. Di antara ayat-ayat al-Qur'an yang menjelaskan hal itu adalah:

Dan tiadalab kami mengutus engkau (Mubammad) melainkan untuk (menjadi) rabmat bagi semesta alam. (alAnbiya', 107)

Al-Quran ini tidak lain banyalab peringatan bagisemesta alam. (Shad, 87)

Dan engkau sekali-kali tidak meminta upab kepada mereka (terbadap seruanmu ini). Itu tidak lain banyalab pengajaran bagi semesta alam. (Yusuf, 104)

Adanya Islam yang alamiah, menunjukkan tanpa keraguan kepada kesemestaan risalah ini, dan fleksibilitasnya, serta kemampuannya yang mutlak

Kemestaan risalan Islam
menunjukkan kasih-sayang
Tulian kepadahamba-Nya, karena
ia adalah risalah rahmah,
keadilan, dan kemanusiaan. la
adalah risalah yang memberi
batas bagi setiap aturan, misi
kemanusiaan, dan segala aturan
buatan manusia yang telah
tersebar di bumi ini Risalah
manakah, atau filsałat manakah,
ataupun ide manakah yang
mampu menembus rintangan-
rintangan, dinding-dinding, dan
batas-batas, dan dapat menetap
dalamsuatubagian besar di alam
luas ini selain Islam?

kemanusiaan, dan segala aturan buatan manusia yang telah tersebar di bumi ini. Risalah manakah, atau filsafat manakah, ataupun ide manakah yang mampu menembus rintangan-rintangan, dinding-dinding, dan batas-batas, dan dapat menetap dalam suatu bagian besar di alam luas ini selain Islam?

Menurut Dr. Lourva Gluriz, seorang peneeliti ahli berkebangsaan Italia: "Ayat Al-Qr'an yang menunjukkan kapada kesemestaan Islam sebagai agama yang ditunkan Allahi kepada nabi-Nya, Muhammad saw (rahmatan li al'alamin) adalah seruang langsung kepada alam semesta. Ini meerupakan satu dalil yang sangat jelas bahwa alam semestal. Ini merupakan satu clalil yang sangat jelas bahwa Rasulullah saw telah merilsakan dengan penuh keyakinan bahna risalahnya telah clitakclirkan akan melampaui batas wilayah teritorial bangsa Arab, yang meliputi berbagai bangsa yang berlainan warna kulit dan bahasanya. memahami segala perubahan zaman, dan perkembangan kehidupan, maupun pandangan manusia itu sendiri terhadap kehidupan ini segala situasi dan kondisinya.

Kemestaan risalah Islam menunjukkan kasihsayang Tuhan kepada hamba-Nya, karena ia adalah risalah rahmah, keadilan, dan kemanusiaan. Ia adalah risalah yang memberi batas bagi setiap aturan, misi
Misi Islam mampu melakukan terobosan dan tersebar clalam setiap setiap clan tempat, karena dia adalah satu-satunya agama yang membawa benihbenih kehidupan hakiki dan mulai bagi umat manusia. Ia mampu mengisi karakter dan pertumbuhannya, memahami semangat dan aspirasinya. Maka dengan demikian manusia menganutnya sebagai hal yang logis dan memuaskan bagi fitrah tanpa paksaan. 


\section{A. Agama Fitrah Kemanusiaan}

Di dalam Islam, ada suatu hakikat (fakta yang sangat positif) clan tidak clapat clibantah lagi kebenarannya yang mengatakan bahwasannya manusia tidak mungkin hidup tanpa iman. Iman itu sendiriadalah suatu perasaan batin yang sangat dalam, yang mendorong manusia bekerja dan menjalani kehidupan ini dengan caral yang positif. Seorang manusia ticlak memilikisuatu kehidupan yang berarti, tanpa mengikutsertakan keimanannya. Yaitu perasaan halus yang memancar bersama dengan kebutuhan akan kekekalan serta terjalinnya komunikasi yang harmonis antara manusia dan kehidupannya.

Tiadla pendorong yang lebih kuat lagi manusia untuk bekerja dan hidup, serta bercita-cita selain iman. Sesungguhnya kebutuhan manusia kepada iman sama dengan kebutuhannya kepada iman sama dengan kebutuhannya kepada udara, air, dan makanan. Dia tidak akan mampu hidup terus tanpa perasaan batin yang memberikan harapan ini. Kita clapat menggambarkan bahwa kehidupan seorang manusia tanpa iman di dunia ini hanya akan dipenuhi dengan kezaliman, dan pemaksaan, tanpa perikemanusiaan. Ia sarah dengan tindakan-tindakan anarkhi, kesia-siaan, dan kehampalan.

Manusia tanpa iman kebaikan bejana yang kosong, tiada kehidupan di dalamnya. Manusia tanpa iman akan berubah menjadi suatu bentuk manusia yang tiada berkeperikemanusiaan, tidak memiliki perhatian selain kepada pemenuhan hawa nafsunya, tidak mempunyai kepedulian kepada orang lain. Bahkan kehidupannya akan berubah menjadi seperti kehiclupan binatang di dalam hutan rimba. Yang kuat berbuat seweng-wenang terhadap orang-orang yang lemah, tanpa belas kasihan.

Islam datang membawa akidah yang selaras dengan fitrah manusia, terjadi dengan segala tuntutan rohaninyal. Akidlah Islam berporos pada keesaan Allah SWT yang tidak dapat dicapai oleh filsafat, pemikiran, clan berbagai macam idleologi yang telah dicoba dan diterapkan oleh manusia dibberbagai tempat pada masa yang berganti-ganti. Kemampuan Islam clalam menanamkan akidah clan memantapkannya, diakui oleh sejarawan Inggris, Arnold J. Toynbee (1988-1975), yang mengattakan: "Islam telah mengembalikan kekuatan keesaan Allah bila dibandingkan dengan kelemahan yang tampak dalam penganut substansi agama Nasrani."

Sesungguhnya Islam adalah agama fitrah kemanusiaan clan sesungguhnya iman adalah tonggak kehidupan Islam, karena dia adalah tonggak kehiclupan Islam; clan tidak mungkin akan tegak istana kehiclupan Islam yang benar kecuali jika clitopang di atas tonggak pengakuan tauhit, karena ia aclalah pengakuan yang sangat esensial bagi manusia untuk mewarnai kehiclupannya, sesuai dengan kehendak Tuhan baginya. Selain itu, manusia juga diharapkan agar merasa bahwa dia adalah salah satu makhluk Allah SWT yang banyak dan tidak terhitung jumlahnya, serta wajib menghadap kepadaNya dengan melakukan ibadah yang ikhlas. Dengan begitu, dia akan memperoleh ketentraman hati dan ketenangan jiwa, lalu clia rela melakukan bakti sosial yang bermanfaat, baik untuk dirinya sendiri maupun untuk sesama umatmanusia.

Sesungguhnya iman yang telah bersemayam di hati manusia, dan telah terpateri menjadi akidah yang kokok baginya, sesuai dengan petunjuk risalah Islam disertai dengan ajaran-ajaran yang praktis bagi Islam, akan memberikan bentuk yang erat hubungannyal dengan anggota badan dan tidak boleh clipisahpisahkan, karena dia adalah contoh yang nyata bagi Islam dalam bentuk, gambaran, dan ajaran-ajarannya. Contoh ini merupakan misal yang murni yang datang 
selaras dengan fitrah manusia. Fitrah inilah yang selalu condong kepada iman, dan selalu menggantungkan diri kepada apa yang sama dengan dirinya, atau lebih rendah claripada dirinya, atau mempersekutukan dua sesembahan dalam sembahannya. Sesungguhnya ia adalah iman yang satu dengan Tuhan yang Esa. Demikianlah, Islam datang untuk membebaskan manusia dari penyembahan hambakepada penyembahan Tuhan segala hamba. Itulah yang dapat memasukkan ketentraman dalam hati clan memberikan ketenangan jiwa. Itulah fitrah Allah SWT yang telah menciptakan manusia seluruhnya pada ciptaan itu.

Seorang Scotlandia, Rax Engrams, yang telah memeluk agama Isalm setelah studi lama dengan penyelidikan mendalam, berkata: "Sesungguhnya aku yakin bahwa Islam adalah agama yang memasukkan kesejahteraan dan ketentraman dalam jiwa, dan mengilhamkan kepadaa manusia kesabaran, ketenangan hati, dan hiburan di dalam kehidupan ini. Sungguh aku telah meresapkan semangat Islam ke dalam jiwaku, maka aku merasakan kenikmatan iman clengan ketetapan Ilahi, tanpa memperdulikan pengaruh materi, baik berupa rasa lezat, maupun berupa rasa sakit. Aku telah meneliti agama Islam beberapa tahun, dan aku tidak menganutnya sebagai agama kecuali setelah melalui penyelidikan yang mendalam, dan analisis kejiwaan yang lama. Aku tidak mengganti agamaku yang clulu, kecuali untuk mendapatkan ketenangan dari keguncangan kehidupan yang gila ini, dan untuk menikmati rasa sakinah, di bawah naungan ketenangan pikiran, jauh dari beban duka di hati, dan bencana yang menyebabkan permusuhan atas perebutan harta benda yang akan memperbudak manusia. Aku menjadi Islam untuk membebaskan pikiran, akal, dan hidupku dari sasaran kehancuran." Inilah fitrah yang sesuai dengan firman Allah SWT:

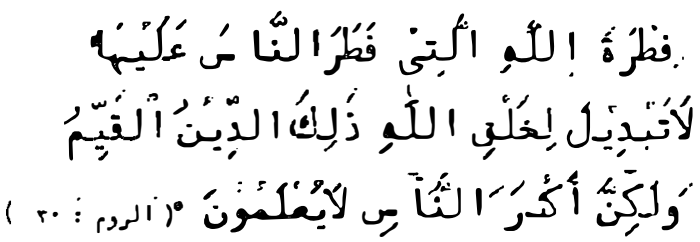

Fitrab Allab SWT yang telab menciptakan manusia menurut fitrab itu. Tidak ada perubaban pada fitrab Allab. Itulab agama Allab yang lurus, tetapi kebanyakan manusia tidak mengetabui. (alRum, 30)

\section{B. Kesemestaan Islam}

Ada dua sifat yang dimiliki Islam clan itulah yang membedakannya dengan agama-agama dan aliranaliran yang lain. Kedua sifat itu adalah: keumuman dan kesemestaannya. Keumuman yang dimaksudkan di sini adalah adanya agama Islam yang bersifat umum bagi seluruh umat manusia, tanpa penentuan dan pembedaan. Ia adalah untuk semua kaum, dan generasi manusia sepanjang masa, sesuai dengan firman Allah SWT clalam al-Al-Qur'an 'an:

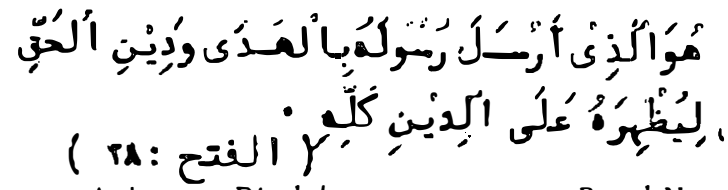

Artinya : Dia-lab yang mengutus Rasul-Nya dengan membawa petunjuk dan agama yang bak, agar dimenangkan-Nya terbadap semua agama. (QS.48 Al-Fath:28).

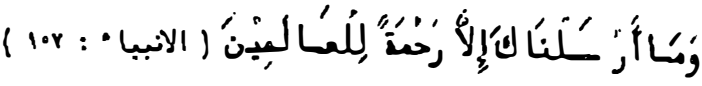

Artinya : Dan tiadalab Kami mengutus engkau (Mubammad) melainkan untuk (menjadi) rabmat bagi semesta alam. (QS.21 Al Anbiyaa:107)

Islam datang dengan keumumannya ini, dan juga datang dengan kesemestaan syari'atnya yang meliputi seluruh aspek kehidupan manusia dan mengaturnya dengan aturan yang selaras clengan seruan iman kepada Yang Maha Pencipta dan Maha Esa. Yang terpenting clalam kesemestaan ini, dapat disimpulkan sebagai berikut:

1. Dalam bidang politik dan hukum;

Kedatangan Islam membawa prinsif bahwa hukum itu adalah milik Allah, seagaimana firman-Nya:

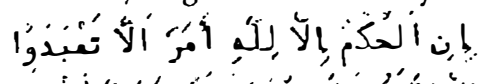

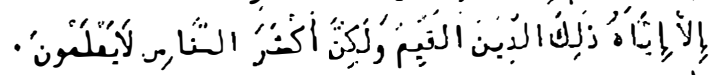

( 
Artinya: Keputusan (bukum) itu banyalab kepunyakan Allab. Diatelab memerintabkan agar kamu tidak menyembab selain Dia. Itulab agama yang lurus, tetapi kebanyakan manusia tidak mengetabui. (Q.S.12 Yusuf:40)

Demikian juga dalam firman-Nya:

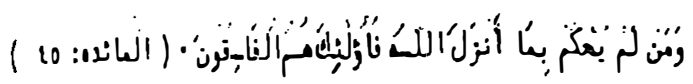

Artinya: Barang siapa memutuskan perkara menumut (bukum) apa yang diturunkan Allab, maka mmereka-mereka itu adalab orang-orang zalim. (Q.S.5 Al Maidah:45)

Demikian juga dalam firman-Nya:

\section{( بونس : 10 (10)

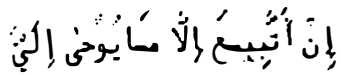

Artinya: Aku tidak mengikuti keculai apa yang divvabyukan kepadaku... (Q.S.10 Yunus:15)

Maka dengan demikian, tasyri' itu hanya clari Allah, Dialah Pencipta syari'ah (undang-undang) untuk hamba-Nya dan tidak boleh bagi seseorang membuat syari'ah untuk clirinya yang berlainan dengan apa yang telah disyari'atkan Allah bagi mereka. Di sinilah harus ditunjukkan bahwasannya tasyri' itu harus berada dalam lingkungan tasyri' Ilahy, dan tidak boleh bertentangan sedikitpun dengannya. Diantara perspektifkeabadian dan keumuman agama ini ialah, adanya tasyri'nya datang clengan sifat kelembutan (fleksibel) tidak kaku, sehingga dapat sesuai dengan perubahan zaman dan pergantian masa, dengan penyesuaian yang clapat menjadi suatu contoh yang dipegangi clengan melihat sasarannya, asal-usulnya, clan tujuannya. Islam tidak menetapkan suatu bentuk tertentu bagi suatu sistem hukum dalam kedaulatan Islam yang tidak boleh clirubah, atau tidak boleh meleset daripadanya; tetapi ia membiarkannya untuk ijektihad (bagi para mujetahidin) dalam menyesuaikan dengan perubahan zaman, sesuai dengan perkembangan kehidupan. Akan tetapi Islam telah menetapkan prinsip-prinsip, dan tradisi hukum Islam berbeda dengan berbagai nama dan istilahyang digelar orang. Sesungguhnya Islam telah menetapkan suatu sistem hukum yang mulia clan tinggi, tiada bandingannya dari sistem hukum positif dewasa ini. Islam telah menetapkan prinsip-prinsip hukum yang adil, ia telah memerintahkan musyawarah dalam sistem yang terbaik dan indah. Ia (Islam) telah menetapkan dengan teguh dasar-dasar dan prinsif-prinsif beban tanggung jawab dalam hukum, dan telah mengatur urusan, atau sistem kedaulatan Islam dengan sistem yang kuat dan indah, serta meletakkan dasar-dasar dan kaedah-kaedah umum tentang hubungan negara Islam dengan daerah-daerahdan negara-negara lain, tentang masalah-masalah perdamaian clan perang, clan meletakkan asas akhlak yang tinggi pada masalah tersebut yang hampir tidak diketemukan bandingannya dari berbagai mazhab atau sistem filsafat, dibanding dengan penguatannya kepada yudikatf dan penetapannya kepacla supermasi hukum clan kemerdekaannya.

\section{Dalam bidang politik ekonomi}

Islam telah meletakkan sistem ekonomi bebas dan bertanggung jawab di dalam lingkaran hukum syari'. Ia membolehkan perdagangan dengan segala bentuknya, dan sistemnya, selama dalam batas-batas yang dibolehkan oleh syari'at Islam, tentang benda-benda yang diperjual-belikan, dan syarat-syarat yang harus dipenuhi para pedagang yang telah dianjurkan oleh Islam yaitu: kebenaran, kejujuran, terpercaya, tiacla penipuan, tiacla pengkhianatan, clan tiacla pemalsuan; Islam juga menganjurkan pekerjaan yang produktif dan percaya cliri sendiri clalam mengusahakan penghidupan dan mencari rizki, dengan menyatakan bahwa "tangan yang diatas (yang bekerja)lebih claripada tangn yang dibawah (yang sengaja mengemis pada manusia). Dalam hadits yang diriwayatkan oleh Bukhari dan Muslim dari Zubair bin 'Awwam r.a. Rasulullah bersabda yang artinya: 


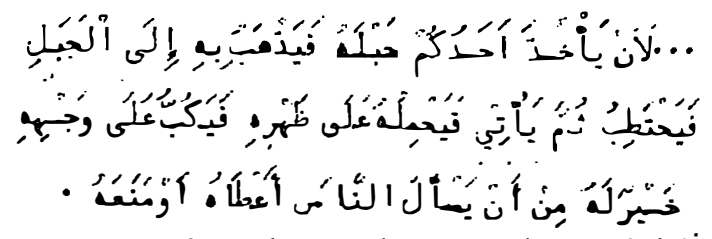

Sesunggubnya diantara kamu membawa tali, lali pergi ke butan mengambil kayu bakar untuk dijual, kemudian ia jatub tertelungkup diwajabnya, lebib baik baginya dari pada meminta (mengemis) kepada manusia, diberi atau tidak diberi. (H.R. Bukhari dan Muslim). menyukai orang-orang yang berlebib-lebihan. ( Q.S. 7 Al A'raf: 31 )

Allah melarang: mencuri, mencopet, menyogok, clan menyalagunakan jabatan untuk kepentingan pribadi atau golongan. Islam telah menetapkan prinsip ekonomi dan kemasyarakatan yang agung dalam kewajiban zakat. Dia merupakan tiang dan jaminan ekonomi masyarakat yang utama dalam negara Islam. Ia mewajibkan pemerintah berusaha mengatur sistem penarikannya, dan penyalurannya kepada yang berhak ( asnaf tsamaniah ) yang telah ditetapkan oleh Al Qur'an clalam ayat 60 surat At Taubah. Zakat merupakan satu-satunya sistem ekonomi clidunia yang mampu memecalkan problem-problem kemiskinan clan segala keperluan yang membutuhkan clana yang cukup. Dia juga merupakan sistem yang mampu mewujuclkan keseimbangan situasi dan kondisi kehidupan diclalam masyarakat yang tiacla bandingannya dalam sistem dunia modern hingga dewasa ini.

Kalau demikian, maka islam adalh pemborosan. Islam mewajibkan kepada negara (pemerintah) mengolah segala kekayaan negara yang hasilnya dapat bermanfaat bagi rakyat dan meningkatkan kekayaan clan devisa negara.

Allah SWT mengharamkan riba karena menimbulkan kehancuran perekonomian masyarakat. Ia menganjurkan infak tanpa pemborosan sebagaimana firman-Nya :

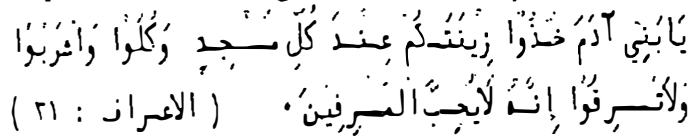

Artinya: Hai anak Adam, pakailab pakaianmu yang indab disetiap memasuki mesjid (melakukan salat). Makan dan minumlab, dan janganlab berlebib-lebiban. Sesunggubnya Allab tidak agama universal, meliputi segala lapangan hiclup lalu mengaturnya dengan aturan yang manusiawi. Dari berbagai aspeknya, ia memperhatikan berbagai perbedaan manusia dalam tingkat ekonomi, sosial, pendidikan clan kebudayaan mereka dalam perkembangan kehidupan melalui peredaran zaman. Hal ini telah diakui oleh kebanyakan orientalis dan lain-lainnya, seperti yang dikatakan oleh seorang tokoh sastra yang terkenal, George Bernard Shau berkebangsaan Inggris kelahiran Irlandia ( 1856-1950) : "Islam menurut pendapat saya adalah satu-satunya agama yang mempunyai daya kekuatan yang hebat, karena sesuai dengan kenyataan kehidupan yang selalu berubah, dia sesuai dengan segala zaman; 


\section{Dalam pendapat saya ( Bernard Shau)} bahwasannya Muhammad (saw) itu, seharusnya digelar sebagai "Penyelamat Kemanusiaan" dalam hal ini, bukan musuh bagi Al Masih dari Al kitab :

" AL JANIBUL KHAFYU WARAA ISLAMI HAULAI

" ( latr belakang keislaman mereka )

\section{Islam adalah Agama Peradaban dan Ilmu Pengetahuan :}

Ayat Al quran yang pertama kali diturunkan kepacla Nabi Muhammad saw. dimulai dengan kata "IQRA" (bacalah) sebagai pernyataan tentang urgensi ilmu dan belajar. Ilmu sebagaimana yang telah kita maklumi adalah jalan peradaban, perkotaan clan kemajuan. Sesungguhnya Islam sangat menganjurkan menuntut ilmu dan menambahkannya seumur hidup, sesuai dengan firman Allah dalam Al Qur'an :

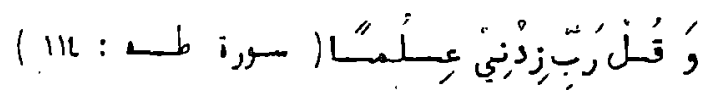

Artinya ; "Dan katakan;lah : "Ya Tubanku tambabkanlab kepadaku Ilmu pengetabuan". ( Al Quran s.20: Thaahaa : 114)

Rasulullah salw. telah menetapkan penebusan diri bagi tawanan perang Badar dengan menghajar ( bacatulis) sepuluh orang dari kaum Muslimin. Ini menunjukkan perhatian Nabi saw. terhadap pentingnya ilmu pengetahuan bagi kaum muslimin, bahkan bagi umat manusia seluruhnya. Dalam hal ini, Mauris Bukay mengatakan : Bahwasalanya Islam itu selalu menganggap bahwa : agama dan ilmu pengetahuan merupakan kembar dua, yang tidak boleh terpisah. Sejak semula perhatiannya dengan ilmu merupakan suatu bagian yang tidak dapat terpisah dari berbagai kewajiban yang diperintahkan Islam. Sesungguhnya realisasi dari perintah inilah yang membawa bersinarnya ilmu pengetahuan yang mengagumkan pada zaman keemasan islam. Dari situlah orang-orang Barat mengambil ilmu pengetahuan itu sebelum Renaisans Eropa. ( Darri kitab : Studi tentang kitab-kitab suci )

Sesungguhnya kedatangan agama islam ini, untuk meluruskan jalan kehidupan manusia dimuka bumi, maka sepantasnya ia menang dan mengalahkan kehidupan sekarang ini, karena ia membawa jaminan kemanusiaan yang hakiki bagi kehidupan manusia. Islam datang membawa ilmu pengetahuan dan keadilan kemanusialan, serta memerintahkan istikamah (tetap) diatas moral fitrah kemanusian. Ia mnyerukan kepedulian sosial dalam berbagai rupa dan bentuknya. Ia menganjurkan kepada seluruh orang yang beriman agar bersedia mengurbankan sebagian dari hasil usahanya untuk tolong-menlong dan rasá simpati. Ia memerintahkan (kaum muslimin) melakukan musyawarah, saling mengingatkan kebenarăan, berbuat kebajikan, dan senantiasa menambah ilmunya. Ia juga menganjurkan agar selalu membuat rencana, berpikir untyuk penemuan-penemuan yang baru. IsIm adalah agama yang praktis yang selalu menghubungkan antara ibadah kepada Allah secara vertikal di mihrab, dan ibadah kepada Allah secara horisontal melalui laboratorium, penelitian, dan pabrik. Itulah ciri-ciri tersendiri dan contoh-contoh khusus bagi islam yang membedakannya dengan berbagai agama, aliran filsafat, teori-teori materealisme, kapitalisme. Inilah yang membawa islam mampu mengatasi segala macam problem sosial, ekonomi dan politik, dengan metode yang sesuai, dan pemecahannya dengan selamat.

Seorang sarjaná sosiolog berkebangsalan yahudi bernama : Ernast Gultoo mengatakan : "Bahwa sesungguhnya islamlah yang paling cocok memecahkan berbagai krisis dewasa ini, baik krisis politik, maupun krisis ekonomi. Sesungguhnya ia telah sukses clalam membendung aliran-aliran atheist, sememtara agama-agama lain gagal menghadapinya, terutama dalam bidang politik. ( clari kitab ; Al Janibul Khafyu Waraa Islami Haulai")

Seorang wanita jerman, setelah memperkenalkan keislamannya dan menanamkan dirinya "Fatimah Lamier", mengatakan :

"Alangkah jelas clan baiknya ajaran islam. Sesungguhnya agama islam adalah agama modern baik sekali dan sangat sesuai dengan zaman kita zaman modern ini. ( carri kitab : Rijalun wanisaun aslamna= Beberapa laki-laki dan perempuan yang telah 
memeluk islam).

Islam yang selalu berseru kepada kemajuan, keadilan sosial, ilmu pengetahuan, penelitian, etos kerja, peningkatan akhlak kemanusiaan, dan contoh pendamai. Kedatangan islam untuk meletakkan batas pertentangan kelas dalam masyarakat, clan membebaskan manusia clari perbudakan patung, manusia, hawa nafsu, da n harta benda. Ia datang untuk memecahkan secara logis dan rasional bagi segala problem manusia, cliberbagai masyarakat dan negara. Agama ini pantas sekali membebaskan masyarakat dari belenggu materealis. Ia mampu memberikan contoh-contoh yang tiada taranya bagi masyarakat yang bersih teratur, berperadaban modern, yang menerapkan peraturan Allah yang merupakan peraturan yang lurus, tidak cliclatangi suatu kebatilan diclepan dan dibelakangnya. "Itulah agama yang lurus tetapi kebanyakan manusia ticlak mengetahui". ( Q.S. $30 \mathrm{Ar}$ Rum : ayat 30). Demikianlah situasi dan kondisi masyarakat yang clituntun oleh nilai-nilai akhlak kemanusiaan, msyarakat kota yang modern.

\section{Islam Ideologi Alternatif di Abad ke 21}

Banyak sekali pikiran telah dicoba diclunia, clan telah banyak pula falsafah clan teori yang telah diterapkan cliberbagai negara, akan tetapi semuanya gagal menciptakan suatu masyarakat yang membawa manusia dalam kehiclupan sejahtera, tentram, amn,.. dan bahagia di dalamnya.

Markisme telah gagal umtuk memberikan kepuasan manusia dengan prinsip atheisnya, karena ia bertenangan dengan fitrah manusia clan kemanusiaan dan logika rasional, clemikian juga penemuan-penemuan ilmiah, dan clinamika perkembangan kehidupan manusia itu sencliri.

Markisme telah melahirkan anak kembar yaitu : sosialisme clan komunisme untuk merealisasi prinsif persamaan clan menghilangkan hak milik pribadi diantara manusia, yaitu: persamaan yang berpusat pacla materi segala-galanya, akan tetapi ia tidak meresapkepacla karakter manusia itu. Para tokoh sosialisme dan komunisme ticlak mengetahui bahwasannya ajaran islam lebih bagus untuk merealisasi prinsip persamaan yang diinginkan clalan sistem ilmiah dan manusiawi, yang selalu menjaga martabat manusia clan hak-hak mereka clalam kehidupan terhormat, diatas prinsip keseimbangan masyarakat yang kokoh, dan sirkulasi keuangan yang sehat, tidak bereclar diantara orang-orang kaya saja.

Prinsip dasar persamaan hak milik sebenarnya clalam islam hanya pada tiga macam sesuatu yaitu : "air, rumput, clan api". Kapitalisme clewasa ini memaksakan kebebasan masyarakat modern dengan suatu paksaan yang menghasilkan beberapa macam rupa clan bentuk dan membuat beberapa macam pertentangan kelas; dimana kelas yang mampu clan mempunyai harta, menguasai kelas lemah dan miskin tujuannya aclalah menumpuk modal kekayaan dan memperbanyak perusahaannya. Yang penting bagi mereka mengumpulkan harta benda dan menciptakan manfaat pribadi, tanpa memperhatikan kemaslahatan umum clan kepentingan lainnya.

Pacla masyarakat kapitalisme dan lebralisme yang ticlak berpegang pacla dasar hukum selain dasar materi yang dikuasai oleh kelompok pemilik modal, lalu mempekerjakan manusia yang terclesak oleh kebutuhan dan kemiskinan. Akibatnya menimbulkan kecemburuan sosial clan kedengkian yang mendalam, serta benterokan yang hebat antara kelas-kelas masyarakat; yang merupakan benturan yang sulit dihentikan tanpa usaha memperbaiki masyarakat itu, sampai terciptanya keseimbangan kehidupan masyarakat.

Masyarakat yang telah menjadi masyarakat bebas dewas ini menderita kegoncangan-kegoncangan yaitukejiwaan, moral, dan clisintegrasi sosial yang 
sanagt parah, karena ia hanya mengutamakan materi kepada manusia dan melakukan prinsipnya yang populer : "Tujuan membolehkan segala cara ", yakni: untuk mencapai tujuan, harus melakukan segala cara.

Seorang pujangga islam yang terkenal : Muhammad Iqbal mengatakan: Kebudayaan barat telah tua dan pikun setelah memerankan peranannya, ia telah masak seperti buah yang telah sampai musimnya dipetik. Dunia yang ada disekitarnya akan mengalami peperangan yang dasyat hingga mengalami kehancuran. Negara-negara Eropa telah melihat dengan matanya sendiri product-product menjadi contoh yang menakutkan dibidang ekonomi, moral, clan, ilmiah. Sesungguhnya kemanusiaan akan bergerak dari dunia baru. Dunia ini tidak akan baik pengaturannya kecuali cliatur oleh yang membangun Baitul Haram untuk kemanusiaan, yang clilaksanakan oleh Nabi Muhammad saw. dan Nabi Ibrahim a.s.

Menurut Walles Aurisoon (1915-1985) :" Agama yang benar yang selalu sejalan dengan zaman modern adalah agama Islam". (Dari kitab: Al Islamu wa hadharatul mustaqbal).

Sesungguhnya kegagalan berbagai filsafat dan ide-ide, serta teori-teori modern dan kegagalan dalam membangun masyarakat yang manusiawi, bersamaan dengan kebutuhan-kebutuhan manusia yang bernilai moral dan spiritual, disamping kebutuhan-kebutuhan materi, adalah seruan kembali kepada ajaran agama Islam yang merupakan ideologi alternatif cli abad XXI (Milenium ketiga). Kembali kepada ajaran agaman Islam disyaratkan reformasi clalam cliri kita masingmasing, karena Allah tidak akan merubah keadlaan kaum sebelum kaum itu melakukan perubahan dari dalam diri mereka. (QS. Ar Ra'd:1). Maka dengan demikian orang-orang mukmin berpeluang melaksanakan ajaran Islam di dunia ini, sebagaimana yang telah clijanjikan Allah clalam firman-Nya :

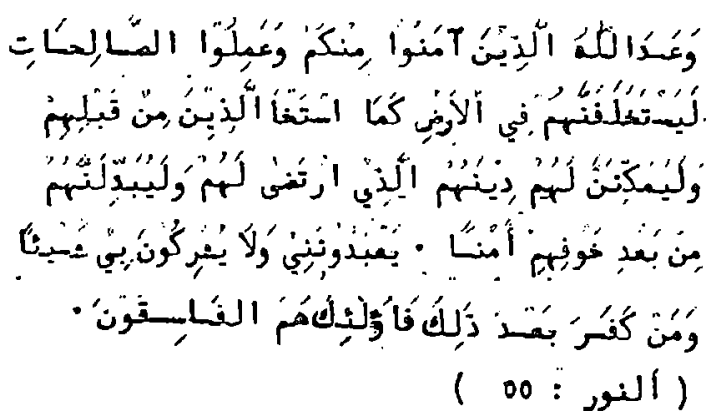

Artinya : Dan Allab telab berjanji kepada orang-orang yang beriman diantara kamu dan mengerjakan amal-amal yang saleb babwa Dia sunggub-sunggub akan menjadikan mereka berkuasa di bumi, sebagaimana Dia telab menjadikan orangorang yang sebelum mereka berkuasa, dan sunggub Diaakan menegubkan bagi mereka agama yang telab diridhai-Nya untuk mereka, dan Dia benar-benar akan menukar keadaan mereka, sesudab mereka berada dalam ketakutan menjadi sentosa. Mereka tetap menyembab-Ku dengan tiada mempersekutukan sesuatu apapun dengan-Ku. Dan barang siapa yang tetap kafir sesudab janji itu, maka mereka itulab orang-orang yang fasik. (QS.24 An Nur:55).

Demikianlah janji Allah yang pastiakan terwujud, cepat atau lambat. Maha besar Allah dengan segala firman-Nya.

\section{Sumber Utama :}

1. Al Alamul Islamy $1418 \mathrm{H}$

2. Al Qur'an \& Terjemahannya, oleh : Departemen Agama RI.

3. Al Aqidah fi LLah oleh : Dr. Umar Sulaiman Al Asyqar

4. al Mujtama'ul Insany oleh :Prof. Muhammad Abu Zahrah. 